\title{
Development of a new Emergency Medicine Spinal Immobilization Protocol for trauma patients and a test of applicability by German emergency care providers
}

\author{
Michael Kreinest ${ }^{1,2}$, Bernhard Gliwitzky², Svenja Schüler ${ }^{3}$, Paul A. Grützner ${ }^{1}$ and Matthias Münzberg ${ }^{1,2^{*}}$
}

\begin{abstract}
Background: In order to match the challenges of quickly recognizing and treating any life-threatening injuries, the $A B C D E$ principles were established for the assessment and treatment of trauma patients. The high priority of spine protection is emphasized by the fact that immobilization of the cervical spine is performed at the very first step in the ABCDE principles. Immobilization is typically performed to prevent or minimize secondary damage to the spinal cord if instability of the spinal column is suspected. Due to increasing reports about disadvantages of spinal immobilization, the indications for performing spinal immobilization must be refined.

The aim of this study was (i) to develop a protocol that supports decision-making for spinal immobilization in adult trauma patients and (ii) to carry out the first applicability test by emergency medical personnel.

Methods: A structured literature search considering the literature from 1980 to 2014 was performed. Based on this literature and on the current guidelines, a new protocol that supports on scene decision-making for spinal immobilization has been developed. Parameters found in the literature concerning mechanisms and factors increasing the likelihood of spinal injury have been included in the new protocol. In order to test the applicability of the new protocol two surveys were performed on German emergency care providers by means of a questionnaire focused on correct decision-making if applying the protocol.

Results: Based on the current literature and guidelines, the Emergency Medicine Spinal Immobilization Protocol (E.M.S. IMMO Protocol) for adult trauma patients was developed. Following a fist applicability test involving 21 participants, the first version of the E.M.S. IMMO Protocol has to be graphically re-organized. A second applicability test comprised 50 participants with the current version of the protocol confirmed good applicability. Questions regarding immobilization of trauma patients could be answered properly using the E.M.S. IMMO Protocol.

Discussion: Current literature increasingly reports of disadvantages that may be associated with immobilization. Based on the requirements of the current guidelines, a new protocol that supports decision-making for indications for out-of-hospital spinal immobilization has been developed in this study. In contrast to established protocols, the new protocol offers different options for immobilization as well as a decicion-support.

Conclusions: The E.M.S. IMMO protocol provides a decision-support tool for indications for spinal immobilization in adult trauma patients that permits variable decision-making depending on the current condition of the trauma patient and the pattern of injuries for immobilization in general and for immobilization method in particular.
\end{abstract}

Keywords: Out-of-hospital, Emergency, Cervical, Spine, Protocol, Algorithm, Immobilization

\footnotetext{
* Correspondence: matthias.muenzberg@bgu-ludwigshafen.de

'BG Trauma Center Ludwigshafen, Department of Trauma Surgery and Orthopaedics, Ludwig-Guttmann-Str. 13, 67071 Ludwigshafen, Germany ${ }^{2}$ PHTLS Europe Research Group, Offenbach/Queich, Germany

Full list of author information is available at the end of the article
} 


\section{Background}

Rapid recognition of any life-threatening injury as well as fast prioritization of treatments that are immediately required may be considered the greatest challenges facing emergency medical personnel in treating trauma patients [1]. To match these challenges, treatment of severely injured patients should follow a structured protocol [2]. Treatment of trauma patients commonly follows the ABCDE concept that provides a clear basis for prioritization (Table 1) [2].

The importance of protecting the spine is emphasized by the fact that immobilization of the cervical spine is performed at the very first step of the ABCDE principles (Table 1). Spinal immobilization is performed primarily to prevent or minimize secondary damage to the spinal cord caused by injuries causing instability of the spinal column [3]. Although previous studies have attributed the frequently observed prehospital neurological deterioration [3] in patients with spinal injuries to the failure of immobilizing the spine $[4,5]$, more recent work has not confirmed this relationship $[6,7]$. Today, it is generally recognized that there is no clear evidence either for or against immobilization [7-10]. Indeed, it is increasingly more important to accept that both the use of a cervical collar and full body immobilization are associated with disadvantages. First, use of a cervical collar on its own does not provide full immobilization of the cervical spine, as there is still considerable residual mobility. This residual mobility is evident in all models of cervical collars that have been tested [11-13]. Thus, to protect the spinal column, full immobilization of head and trunk is necessary [14-16]. Moreover, a cervical collar can result in compression of the jugular veins [17] and hence can lead to a significant increase in intracranial pressure [18-22]. Even full body immobilization, for example on a spine board, is not without complications. In healthy young subjects, complete immobilization was associated with restrictive effects on pulmonary function [23]. In general, airway management is impeded in immobilized patients [24, 25]. Immobilization on a spine board may also cause pain [26-28] and may result in pressure ulcers [29].

Immobilization of the spine in general and of the cervical spine in particular has been a standard procedure in prehospital treatment of trauma patients for many

Table 1 The ABCDE concept for treating trauma patients

\begin{tabular}{ll}
\hline A & Airway/Cervical Spine Protection \\
B & Breathing \\
C & Circulation \\
D & Disability \\
E & Exposure/Environment \\
\hline
\end{tabular}

decades $[8,9]$. However, due to the potential for complications cited above, spinal immobilization should not be performed on a routine basis but only if there are given indications, as it is also required by current guidelines [30-33]. As the severity of patient's injuries increases, the likelihood of an associated spinal injury also increases [34]. However, clear prioritization of all procedures is especially imperative in such patients, as full immobilization of trauma patients can also be associated with delays [35] and even increase mortality, for example in patients with penetrating trauma [36]. Therefore, it is to question if severly injured patients should always be immobilized even if they have a higher probability of spinal injury. The guidelines recommend the use of a decision-support tool to facilitate a rapid and valid on scene decision [30, 31, 33].

A number of decision-support tools have been described in the literature. Some were initially designed for indications for radiological imaging in emergency rooms and were later on tested for sensitivity and specificity concerning the indications for prehospital spinal immobilization [37]. Applicability of many decision-support tools is subject to many limitations. For example, the majority of decision tools were developed for conscious and oriented patients [38, 39]. Many decision tools preclude penetrating [40-42] or blunt injuries [43]. Often, the current status of the patient (stable or unstable) is not considered [39, 41, 44] or the decision tool is only applicable if circulation is already stabilized [38]. Other decision-support tools are designed specifically for victims of motorcycle accidents [45] and not for general use. To our knowledge, there is no universally applicable protocol that supports decision-making for indications for spinal immobilization being valid for all adult trauma patients including the severly injured with unstable condition.

The aim of this study was (i) to develop a protocol as a decision-tool for indications for spinal immobilization in adult trauma patients and (ii) to carry out the first applicability tests of this protocol by emergency medical personnel by means of a questionnaire. The decisionsupport tool should be based on current literature and should orientate on the established ABCDE principles of trauma care. The differentiated consideration of various methods of immobilization and their potentials for complication should be taken into account as well as the patient's condition into the new Emergency Medicine Spinal Immobilisation (E.M.S. IMMO) Protocol.

\section{Methods}

The current study has been approved by the ethical committee in charge (Ethics committee of the State Medical Association Rhineland-Palatinate, Mainz, Germany) under the reference number 837.371.13 (9056). 


\section{Development of the E.M.S. IMMO Protocol}

A structured search of the United States National Library of Medicine and the National Institutes of Health database was performed using MEDLINE through PubMed (www.pubmed.gov). The search terms used are listed in Table 2. We considered the literature from 1980 to 2014. Only articles written in english or german were viewed. Additional articles listed in the reference sections of these articles were also included. Original articles as well as review articles and articles about current guidelines were included. All articels found by the literature search were read full text by the authors.

A new protocol that supports on scene decisionmaking for indications for spinal immobilization was developed based on the protocols found in the literature and taking into account the mechanisms and factors that increase the likelihood of spinal injury in an accident. Most of the parameters found in the literature were included in the new protocol. If contrary statements about spinal immobilization were found in the literature, the more scientifically substantiated statement was included in the current protocol. These decisions are discussed in detail.

\section{Testing the applicability of the E.M.S. IMMO Protocol}

We surveyed German emergency rescue personnel and German emergency doctors in order to test the applicability of the new protocol for indications for spinal immobilization. The questionnaire included four questions about the E.M.S. IMMO Protocol (Fig. 3). After this survey, the protocol had to be revised based on the results of the questionnaire. After the revision, the new protocol was assessed again by the same questionnaire by German emergency personnel and German emergency doctors (not including the former participants). The questions of the first and second evaluations were identical (Fig. 3). All questions were evaluated using a scale of 1-6 (1= "I agree completely", $6=$ "I disagree completely").

Table 2 Search terms utilized in PubMed

\begin{tabular}{l} 
Cervical spine immobilization \\
Cervical spine immobilisation \\
Spine AND motion \\
Spine AND protocol \\
Spine AND ((prehospital) OR (out-of-hospital) OR) \\
(Spine AND injury) AND ((prehospital) OR (out-of-hospital)) \\
(Spine immobilization) AND ((prehospital) OR (out-of-hospital)) \\
(Spine immobilisation) AND ((prehospital) OR (out-of-hospital)) \\
((Spine injury) OR (spine trauma)) AND ((prehospital) OR (out-of-hospital)) \\
\hline
\end{tabular}

\section{Statistics}

Only fully completed questionnaires were included in the analysis. All data were evaluated at a descriptive level (median, interquartile range) and are presented as boxplots with outliers. The analysis was performed using SPSS for Windows, Version 22.0.

\section{Results}

\section{Literature search}

The literature search, carried out as described above, yielded 162 articles after removing duplicates. A reference analysis found additional 34 articles. Thus, a total of 196 articles were included and read in full text. The key conclusions were summarized in table format.

\section{Development of the E.M.S. IMMO Protocol}

Since treatment of trauma patients according to ABCDE principles (Table 1) is already established in resuscitation room care (e. g. Advanced Trauma Life Support) and in prehospital treatment (e. g. Pre Hospital Trauma Life Support), the E.M.S. IMMO Protocol was also based on the $\mathrm{ABCDE}$ principle (Fig. 1).

If possible, immobilization of the cervical spine should always take place immediadetly at initial contact to the trauma patient $[2,31]$. In order to avoid delays caused by positioning a cervical collar prior to assessing the patient following the $\mathrm{ABCDE}$ principles, immobilization can be achieved by restraining the head using hands (Fig. 2a1) or forearms (Fig. 2a2) [46]. The so-called manual in-line stabilization is maintained throughout the $\mathrm{ABCDE}$ assessment and treatment of the trauma patient. Whenever possible, all procedures performed on a trauma patient (e. g. airway management, turning maneuvers, etc.) should be performed with a minimum of further manipulation of the spine in general and in the cervical spine in particular.

Trauma patients should be placed supine for initial assessment and further treatment while manual in-line stabilization is maintained. The cervical spine should be placed in neutral position.

If the assessment of a trauma patient indicates unstable circulation conditions ( $\mathrm{C}$ according to the $\mathrm{ABCDE}$ principles, Table 1), priority for transportation is high. In the event of blunt trauma, immobilization may be minimized using just a cervical collar (Fig. 1). Although the use of a cervical collar alone (Fig. 2b) does not adequately restrict the mobility of the cervical spine [14-16], the residual mobility is accepted in this case, taking into account that complete immobilization would delay expeditious transport and thus could lead to increased mortality. According to the literature, trauma patients with unstable circulation following penetrating trauma should not be immobilized (Fig. 1), because the benefits are regarded as highly questionable [33, 36, 43, 47, 48]. Assessment of a 


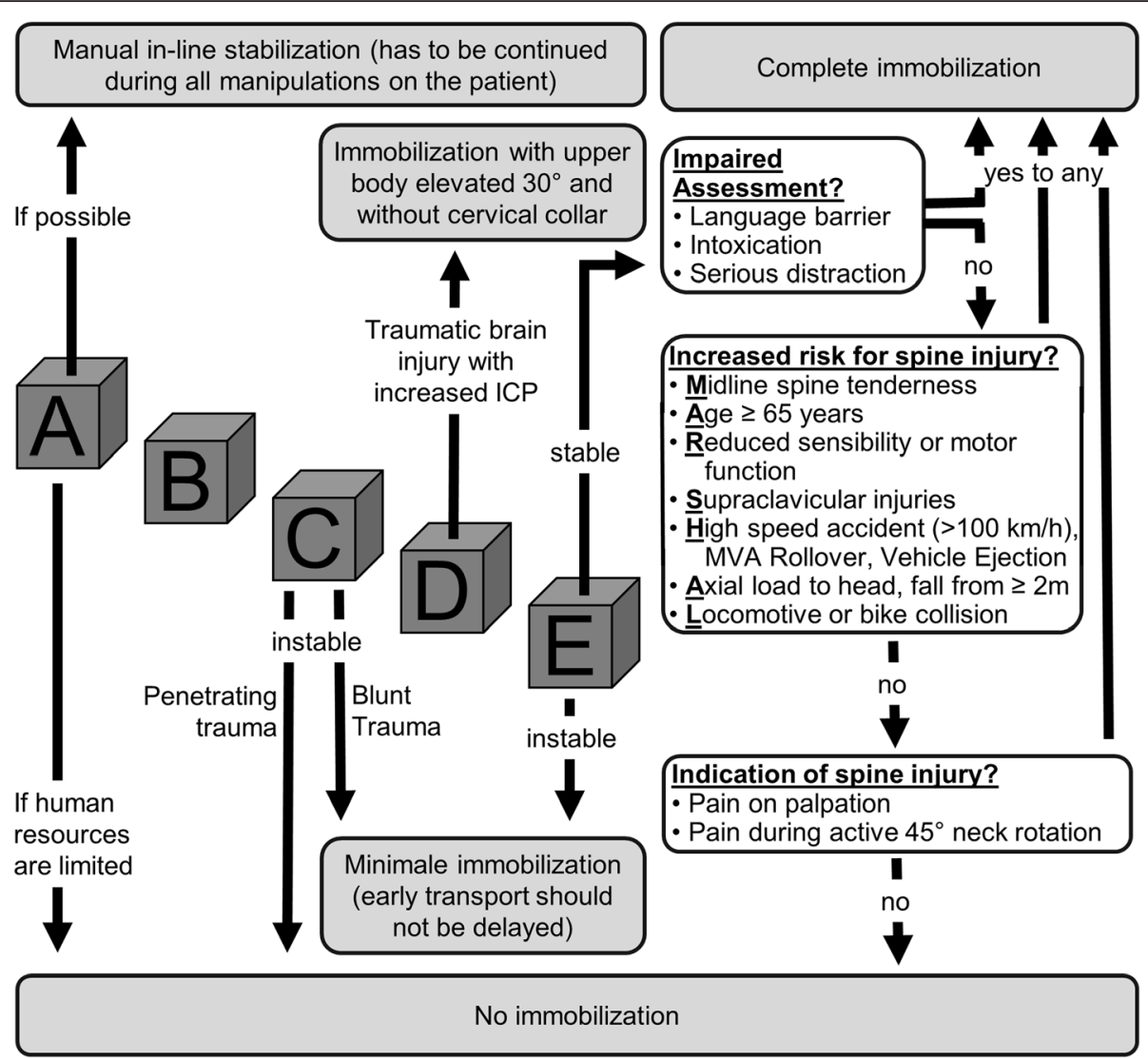

Fig. 1 E.M.S. IMMO Protocol for adult trauma patients. The ABCDE concept is a central element of the protocol. Depending on the status of the patient, differentiated indications for various options for spinal immobilization are followed. For stable patients, the indication is based on the MARSHAL criteria and examination of the cervical spine, after the assessment of the patient has been evaluated as appropriate (ICP = intracranial pressure)

trauma patient for neurological deficit (D, Table 1) should include determining if there are signs of severe brain injury or craniocrebral trauma with increased intracranial pressure. If there are signs of increased intracranial pressure (Table 3), the E.M.S. IMMO Protocol recommends that no cervical collar is used (Fig. 1), as this may cause further significant increases to intracranial pressure [20-22]. However, because cervical spine injuries often coincide with craniocerebral trauma [34], immobilization using the vacuum mattress is recommended [31]. Even without a cervical collar, modern vacuum mattresses could prove to achieve good immobilization (Fig. 2c). Moreover, a position with the upper body elevated $30^{\circ}$ is possible (Fig. 2c), which is also recommended for patients with craniocerebral trauma [31]. Alternatively, the patient may be immobilized on a spine board, with which it has been show that complete immobilization is possible even without the use of a cervical collar [25].

Patients who initially are in a stable circulation condition and no indications of increased intracranial pressure are obvious should have outer clothing removed and should then being examined in more detail (E, Table 1). Afterwards, a decision about transport priority has to be made. Therefore, a review of whether the patient's condition is acute and life-threatening should be made. If so, there is high priority for transport and again only minimal immobilization of the cervical spine is performed using a cervical collar (Figs. 1 and $2 \mathrm{~b}$ ) for the reasons described above. If the patient is in a stable condition, it is necessary to assess the indications for full body immobilization, for example using a spine board (Fig. 2d) or vacuum mattress or whether the manual immobilization (Fig. 2a) that was maintained up to this point can be anulled. Criteria based on the literature were developed to support decision-making either for or against spinal immobilization. Table 4 provides an overview of the criteria found in the literature and indicates whether they were integrated into the E.M.S. IMMO Protocol.

The first assessment to be made is whether the stable patient can be adequately assesed (Fig. 1). An adequate assessment is not possible if there are language 

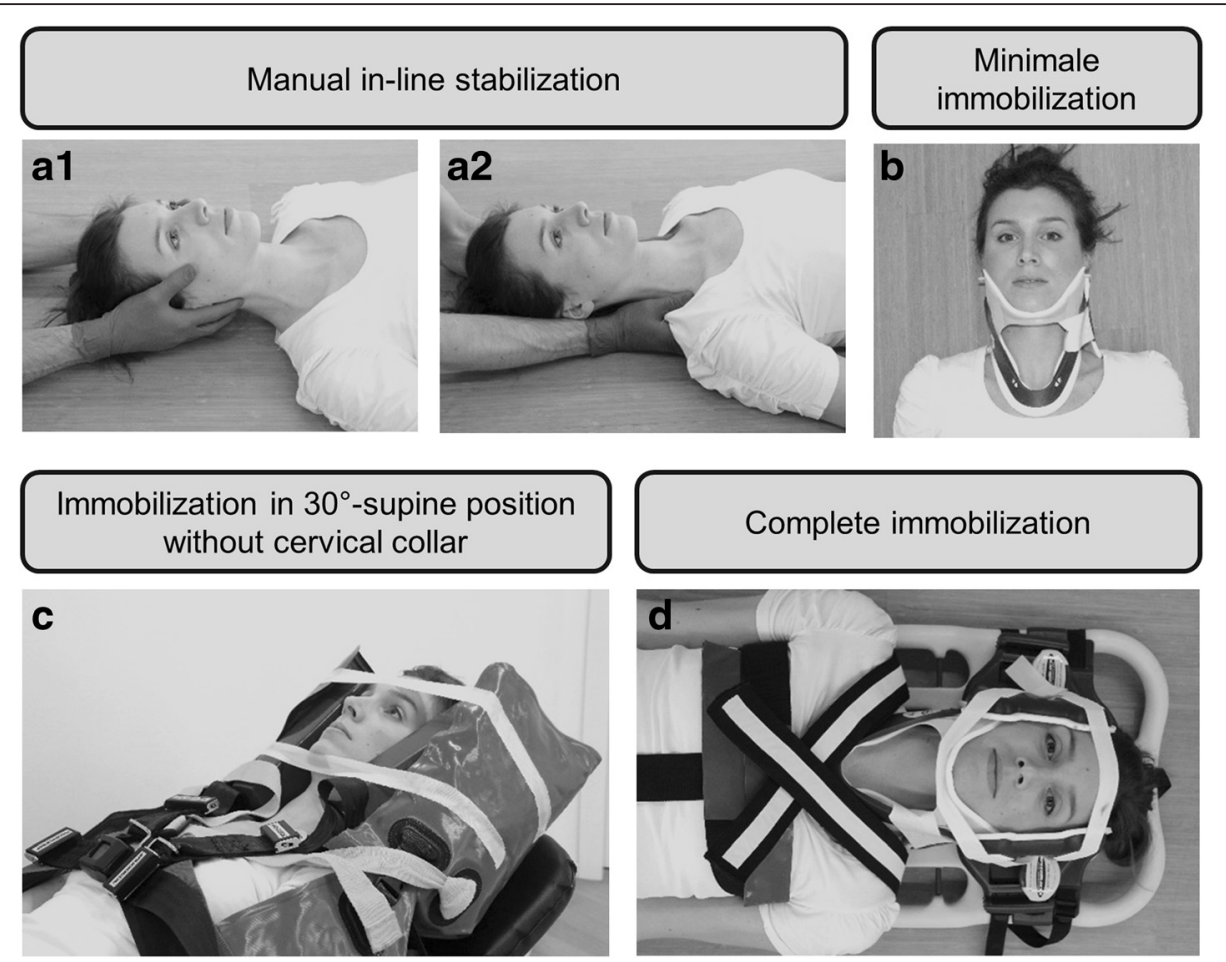

Fig. 2 The different types of immobilization using the E.M.S. IMMO Protocol. Every trauma patient should first be stabilized using manual immobilization of the cervical spine (a). Patients who are unstable and with high transport priority should receive only minimal immobilization using a cervical collar (b). Immobilization of patients who show signs of increased intracranial pressure is achieved in the vacuum mattress in a $30^{\circ}$ position with elevated upper body and no cervical collar (c). Complete immobilization may be indicated for patients who are haemodynamically stable (d). [Note: The model used in these photographs gave her permission for publication]

barriers or other difficulties concerning clear communication (e. g. intoxication). If assessment is inadequate there is indication for complete immobilization. Situations that divert the patient's attention, such as distracting injuries, states of anxiety as well as seriously injured or deceased relatives in an accident are all included under the term "serious distractions". Assesment

Table 3 Evidence of an increase in intracranial pressure following craniocerebral trauma

\begin{tabular}{ll}
\hline $\begin{array}{l}\text { Possible indications of increased } \\
\text { intracraniall pressure: }\end{array}$ & Reduced vigilance \\
& Drop on Glasgow coma scale by $\geq 2$ \\
& Delayed pupil response \\
& Development of hemiparesis \\
$\begin{array}{ll}\text { Definitive indications of increased } \\
\text { intracranial pressure: }\end{array}$ & Both pupils dilated \\
& Anisocoria and reduced vigilance \\
& Bending and stretching synergisms \\
& Cushing's triad \\
& - Hypertension \\
& - Bradycardia \\
& - Pathological breathing pattern \\
\hline
\end{tabular}

of the patient is limited by such distractions and the indication for complete immobilization (Fig. 1) is given. If assessment of the patient is not limited, factors that are associated with higher risk of spine injury can be evaluated (Table 4). These criteria are integrated into the E.M.S. IMMO Protocol as the MARSHAL criteria (Fig. 1). The MARSHAL criteria summarize the criteria mentioned in the current literature (Table 4) in a short and clear manner and are part of the E.M.S. IMMO Protocol. According to these criteria, full-body immobilization should take place if at least one of the MARSHAL criteria (midline spine tenderness; age $\geq 65$ years; reduced sensibility or motor function; supraclavicular injuries; high speed accident $(>100 \mathrm{~km} / \mathrm{h})$, MVA rollover, vehicle ejection; axial load to head, fall from $\geq 2 \mathrm{~m}$; locomotive or bike collision) is confirmed. If all MARSHAL criteria can be positively excluded, the spine should be examined for pain or tenderness under manual pressure (Fig. 1). If this examination yields no pathological findings, the patient should be asked to actively turn the head $45^{\circ}$ to both left and right side (Fig. 1). If this motion of the cervical spine is also possible without pain, immobilization is not necessary (Fig. 1). 
Table 4 Criteria PRO and CONTRA spinal immobilization taken from literature search and integration into the E.M.S. IMMO Protocol

\begin{tabular}{|c|c|c|}
\hline PRO criteria & References & E.M.S. IMMO protocol \\
\hline Age $>65$ years & {$[4,21,43]$} & included in MARSHAL criteria \\
\hline Rigid vertebral disease & {$[52]$} & not included as PRO criteria \\
\hline State of acute anxiety & {$[53]$} & included in MARSHAL criteria (serious distraction) \\
\hline Language barrier & {$[53]$} & included in assessment of impairment \\
\hline Acute stress reaction & {$[54]$} & included in MARSHAL criteria (serious distraction) \\
\hline Distracting injury & {$[42,44,54]$} & included in MARSHAL criteria (serious distraction) \\
\hline Intoxication & {$[52,54-56]$} & included in assessment of impairment \\
\hline Fall from $>6 m$ & {$[57]$} & included in MARSHAL criteria (fall from $\geq 2 \mathrm{~m}$ ) \\
\hline Fall from 3 to $6 \mathrm{~m}$ & {$[57]$} & included in MARSHAL criteria (fall from $\geq 2 \mathrm{~m}$ ) \\
\hline Fall from $>3 \mathrm{~m}$ & {$[52,58]$} & included in MARSHAL criteria (fall from $\geq 2 \mathrm{~m}$ ) \\
\hline Fall from $>2 m$ & {$[59]$} & included in MARSHAL criteria (fall from $\geq 2 \mathrm{~m}$ ) \\
\hline Fall from $>1 \mathrm{~m}$ & {$[38,44]$} & not included as PRO criteria \\
\hline Fall from large animal & {$[57]$} & included in MARSHAL criteria (fall from $\geq 2 \mathrm{~m}$ ) \\
\hline High speed accident > 100 km/h & {$[38,44,52]$} & included in MARSHAL criteria \\
\hline Speed $>56 \mathrm{~km} / \mathrm{h}$ & {$[58]$} & not included as PRO criteria \\
\hline MVA or pedestrian vs. train & {$[57]$} & included in MARSHAL criteria (locomotive or bike collision) \\
\hline MVA ejection & {$[38,44,57]$} & included in MARSHAL criteria \\
\hline Vehicle rollover & {$[38,44]$} & included in MARSHAL criteria \\
\hline Bicycle collision & {$[38,44]$} & included in MARSHAL criteria \\
\hline Road traffic collision & {$[59]$} & not included as PRO criteria \\
\hline Significant intrusion of vehicle & {$[44]$} & not included as PRO criteria \\
\hline Axial load to head & {$[38,44]$} & included in MARSHAL criteria \\
\hline Diving accident & {$[52]$} & included in MARSHAL criteria (axial load to head) \\
\hline Sport injuries & {$[59]$} & not included as PRO criteria \\
\hline Shooting & {$[59]$} & not included as PRO criteria \\
\hline Death at scene & {$[58,60]$} & not included as PRO criteria \\
\hline Altered/loss of consciousness & {$[52-56,61,62]$} & included in ABCDE criteria (unstable patient) \\
\hline Spine pain/tenderness & {$[4,11,20,21,24,41,49]$} & included in MARSHAL criteria and in indication of spine injury \\
\hline Abnormal sensory/motor exam & {$[44,45,52,55,56,62]$} & included in MARSHAL criteria \\
\hline Significant head or facial injury & {$[52,58,61]$} & included in MARSHAL criteria (supraclavicular injuries) \\
\hline Other spine fractures & {$[52]$} & not included as PRO criteria \\
\hline Supraclavicular lesions & {$[45]$} & included in MARSHAL criteria \\
\hline Severe injuries to other body systems & {$[52,55,56,58,61]$} & not included as PRO criteria \\
\hline CONTRA criteria & References & E.M.S. IMMO protocol \\
\hline No neurological abnormalities & {$[39,50]$} & included in MARSHAL criteria \\
\hline No evidence of intoxication & {$[39,50,63]$} & included in assessment of impairment \\
\hline No midline C-spine tenderness & {$[39,50]$} & included in MARSHAL criteria \\
\hline No distracting injury & {$[39,50,63]$} & included in assessment of impairment \\
\hline Able to actively rotate neck & {$[38,44]$} & included in indication of spine injury \\
\hline Penetrating trauma & {$[33]$} & not included as CONTRA criteria \\
\hline Functional range-of-motion & {$[64]$} & included in indication of spine injury \\
\hline
\end{tabular}


The isolated use of a cervical collar does not provide adequate immobilization of the cervical spine [14-16] as described before. Nevertheless, cervical spine protection can be significantly improved by additionally immobilizing the trunk and extremities [15]. Complete immobilization can be achieved by also immobilizing the head [49]. Therefore, the E.M.S. IMMO Protocol does not distinguished between immobilization of the cervical spine and the remainder of the spine, since full-body immobilization should always be performed if there are indications of spine injury for the reasons given in the E.M.S. IMMO Protocol. Reduced immobilization using a cervical collar on its own and positioning in-line on the stretcher is only acceptable for patients in critical condition and with high priority for transport where ensuring rapid transport is essential (Fig. 1). According to the authors opinion, patients in stable conditions who were assessed for high risk of spinal injuries according to the E.M.S. IMMO Protocol should not be immobilized by a stand alone cervical collar.

\section{Applicability tests of the E.M.S. IMMO Protocol}

In order to test the applicability of the E.M.S. IMMO Protocol, we planned to survey 50 German emergency medical care providers and emergency doctors. A first version of the E.M.S. IMMO Protocol was prepared (not shown). In the intermediate evaluation after $n=21$ fully completed questionnaires, the consensus was that the E.M.S. IMMO Protocol was easy to apply (Fig. 3). However, questions 2-4 were frequently answered incorrectly (Fig. 3). The E.M.S. IMMO Protocol was therefore redesigned graphically to its current version (Fig. 1) since understanding problems seems to be based on graphic design.

The applicability of the current version of the E.M.S. IMMO Protocol (as shown in Fig. 1) was confirmed in a second survey of a different set of participants $(n=50)$. Furthermore, responses to questions 2-4 regarding immobilization of trauma patients were now improved (Fig. 3). In question 2 the median was reduced from 2 to 1 (interquartile range $\{1,2\}$ in both cases) were 1 was considered the right answer. In question 3 the median was increased from 5 to 6 (interquartile range changed from $\{5,6\}$ to $\{4,6\})$ were 6 was considered the right answer. In question 4 the median was reduced from 4 to 2 (interquartile range $\{1,5\}$ reduced to $\{1,2\}$ were 1 was considered the right answer (Fig. 3).

\section{Discussion}

Based on the current literature and the requirements of the current guidelines, this study developed a protocol that supports decision-making for indications for outof-hospital spinal immobilization. By integrating the decision-making process with the principles of the

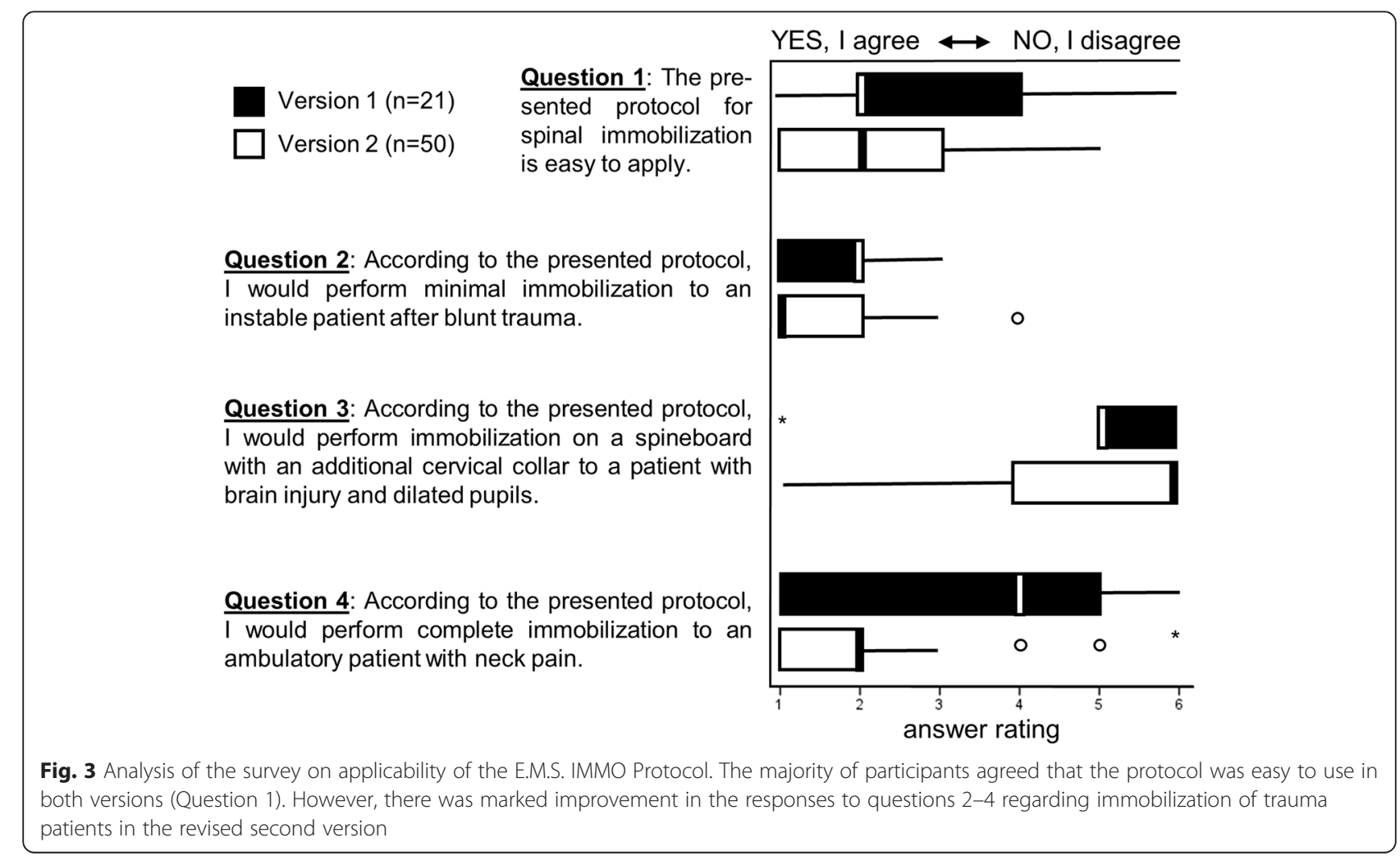


well known $\mathrm{ABCDE}$ principles for the care of trauma patients, we designed a dynamic protocol that orientates first on the current patient's condition. Depending on the patient's circulatory state, the protocol determines, for example, whether further evaluation of the spine is required or should be skipped because of high priority for transport. This should avoid immobilization procedures in unstable patients causing transport delay and thus increasing mortality. In contrast to established protocols $[38,50]$, the E.M.S. IMMO Protocol offers not only a decision-support tool to address whether immobilization is indicated or not, but also distinguishes between different options for immobilization. Hence, a patient with severe craniocerebral trauma and elevated intracranial pressure benefits from immobilization without a cervical collar, because this device may contribute to a further significant increase in intracranial pressure $[20,22]$. To date, many protocols have considered the mechanisms of injury. Hence, there are specific protocols for penetrating [40-42] or blunt [43] trauma. The E.M.S. IMMO Protocol proposes no immobilization for unstable trauma patients following penetrating injury, because no benefits of immobilization have been demonstrated [33, 36, 43, 47, 48]. If a patient has suffered a penetrating injury with neurological symptoms but has stable circulation, which is assessed under $C$ as well as $D$ according to the $\mathrm{ABCDE}$ principles, full-body immobilization is performed based on the MARSHAL criteria.

There are increasing reports of disadvantages that may be associated with immobilization. For example, immobilization may cause restrictive effects on pulmonary function [23], airway management may be impeded [24, 25] and pressure ulcers [29] and pain [26-28] may result. Generalized full-body immobilization of every trauma patient is therefore not advocated by the E.M.S. IMMO Protocol. Application of the new formulated MARSHAL criteria and the subsequent examination of the spine result in differentiated indications for stable patients in order to avoid unnecessary immobilization but providing immobilization for those patient that really have a increased risk of spinal trauma. If a patient cannot be adequately assessed, complete immobilization should take place as a precaution.

The MARSHAL criteria were expressed for the E.M.S. IMMO Protocol on the basis of criteria from the recent literature. The majority of criteria that were formulated after comprehensive literature searches have been integrated into the E.M.S. IMMO Protocol. A few criteria were intentionally not adopted, as their wording was too generalized (e.g. road traffic collision, significant intrusion of vehicle, sport injuries). Other criteria are difficult to identify in a prehospital setting (e.g. other spine fractures) and were therefore not incorporated into the
MARSHAL criteria. Criteria like high speed accidents are defined different in the current literature $(>100 \mathrm{~km} / \mathrm{h}$ vs. $>56 \mathrm{~km} / \mathrm{h}$ ). Vaillancourt et al. could show that a threshold value of $100 \mathrm{~km} / \mathrm{h}$ seems to be sufficient even for high sensitivity of an immobilization protocol $[37,51]$. Therefore, this value was included into the E.M.S. IMMO Protocol.

One weakness of the study is the low number of participants in the first applicability tests. A multicentric study with a greater number of representative participants is required. In addition, a multicentric study should evaluate the sensitivity and specificity of the E.M.S. IMMO Protocol.

\section{Conclusions}

The E.M.S. IMMO Protocol provides a new decisionsupport tool for indications for spinal immobilization in adult trauma patients that permits variable decisionmaking depending on the current condition of the trauma patient and the pattern of injuries. Furthermore, decision-support is given for different immobilization methods depending on the patient's current condition and pattern of injury.

\section{Consent}

Written informed consent was obtained from the person for the publication of the images.

\section{Competing interests}

MK and MM are Medical Course Directors for PHTLS Germany. MM is furthermore ATLS Course Director and National Medical Director for PHTLS Germany and Chair of the PHTLS Europe Research Group.

BG is Instructor for PHTLS Germany. BG is furthermore PHTLS chair of Germany. SS and PAG confirm having no conflict of interest.

\section{Authors' contribution}

MK and MM participated in the design of the study and reviewed the literature. MK, MM and BG developed the protocol. SS performed the statistical analysis. PAG participated in the design of the study and study coordination. All authors helped to draft the manuscript and approved the final version.

\section{Acknowledgements}

We thank Sarah Goller for help with structured literature research. We thank Sabine Kreinest for data management and assistance with graphical presentation of the E.M.S. IMMO protocol. We thank Lisa Ludes for help with the photography.

\section{Author details}

'BG Trauma Center Ludwigshafen, Department of Trauma Surgery and Orthopaedics, Ludwig-Guttmann-Str. 13, 67071 Ludwigshafen, Germany. ${ }^{2}$ PHTLS Europe Research Group, Offenbach/Queich, Germany. ${ }^{3}$ University of Heidelberg, Institute for Medical Biometry and Informatics, Heidelberg, Germany.

Received: 24 December 2015 Accepted: 10 May 2016

Published online: 14 May 2016

\section{References}

1. Davis JW, Hoyt DB, McArdle MS, Mackersie RC, Eastman AB, Virgilio RW, Cooper G, Hammill F, Lynch FP. An analysis of errors causing morbidity and mortality in a trauma system: a guide for quality improvement. J Trauma. 1992;32:660-5. discussion 665-666. 
2. Wölfl CG, Bouillon B, Lackner CK, Wentzensen A, Gliwitzky B, Groß B, Brokmann J, Hauer T. Prehospital Trauma Life Support ${ }^{\oplus}$ (PHTLS ${ }^{\oplus}$ ). Der Unfallchirurg. 2008;111:688-94.

3. Benger J, Blackham J. Why do we put cervical collars on conscious trauma patients? Scand J Trauma Resusc Emerg Med. 2009;17:44.

4. Toscano J. Prevention of neurological deterioration before admission to a spinal cord injury unit. Paraplegia. 1988;26:143-50.

5. Brunette DD, Rockswold GL. Neurologic recovery following rapid spinal realignment for complete cervical spinal cord injury. J Trauma. 1987;27:445-7.

6. Hauswald M, Ong G, Tandberg D, Omar Z. Out-of-hospital spinal immobilization: its effect on neurologic injury. Acad Emerg Med. 1998;5:214-9.

7. Abram S, Bulstrode C. Routine spinal immobilization in trauma patients: what are the advantages and disadvantages? Surgeon. 2010;8:218-22.

8. Sundstrom T, Asbjornsen H, Habiba S, Sunde GA, Wester K. Prehospital use of cervical collars in trauma patients: a critical review. J Neurotrauma. 2014;31:531-40

9. Hood N, Considine J. Spinal immobilisaton in pre-hospital and emergency care: A systematic review of the literature. Australas Emerg Nurs J. 2015;18:118-37.

10. Deasy C, Cameron P. Routine application of cervical collars-what is the evidence? Injury. 2011:42:841-2.

11. Askins V, Eismont FJ. Efficacy of five cervical orthoses in restricting cervical motion. A comparison study. Spine (Phila Pa 1976). 1997;22:1193-8.

12. McCabe JB, Nolan DJ. Comparison of the effectiveness of different cervical immobilization collars. Ann Emerg Med. 1986;15:50-3.

13. James CY, Riemann BL, Munkasy BA, Joyner AB. Comparison of Cervical Spine Motion During Application Among 4 Rigid Immobilization Collars. J Athl Train. 2004;39:138-45.

14. Horodyski M, DiPaola CP, Conrad BP, Rechtine 2nd GR. Cervical collars are insufficient for immobilizing an unstable cervical spine injury. J Emerg Med. 2011;41:513-9

15. Chandler DR, Nemejc C, Adkins RH, Waters RL. Emergency cervical-spine immobilization. Ann Emerg Med. 1992;21:1185-8.

16. Hostler D, Colburn D, Seitz SR. A comparison of three cervical immobilization devices. Prehosp Emerg Care. 2009;13:256-60.

17. Stone MB, Tubridy CM, Curran R. The effect of rigid cervical collars on internal jugular vein dimensions. Acad Emerg Med. 2010;17:100-2.

18. Davies G, Deakin C, Wilson A. The effect of a rigid collar on intracranial pressure. Injury. 1996;27:647-9.

19. Kolb JC, Summers RL, Galli RL. Cervical collar-induced changes in intracranial pressure. Am J Emerg Med. 1999;17:135-7.

20. Craig GR, Nielsen MS. Rigid cervical collars and intracranial pressure. Intensive Care Med. 1991;17:504-5.

21. Hunt K, Hallworth S, Smith M. The effects of rigid collar placement on intracranial and cerebral perfusion pressures. Anaesthesia. 2001;56:511-3.

22. Mobbs RJ, Stoodley MA, Fuller J. Effect of cervical hard collar on intracranial pressure after head injury. ANZ I Surg. 2002;72:389-91.

23. Bauer D, Kowalski R. Effect of spinal immobilization devices on pulmonary function in the healthy, nonsmoking man. Ann Emerg Med. 1988:17:915-8.

24. Goutcher CM, Lochhead V. Reduction in mouth opening with semi-rigid cervical collars. Br J Anaesth. 2005:95:344-8.

25. Holla M. Value of a rigid collar in addition to head blocks: a proof of principle study. Emerg Med J. 2012;29:104-7.

26. Cordell WH, Hollingsworth JC, Olinger ML, Stroman SJ, Nelson DR. Pain and tissue-interface pressures during spine-board immobilization. Ann Emerg Med. 1995;26:31-6.

27. Chan D, Goldberg R, Tascone A, Harmon S, Chan L. The effect of spinal immobilization on healthy volunteers. Ann Emerg Med. 1994;23:48-51.

28. Chan D, Goldberg RM, Mason J, Chan L. Backboard versus mattress splint immobilization: a comparison of symptoms generated. J Emerg Med. 1996;14:293-8.

29. Berg G, Nyberg S, Harrison P, Baumchen J, Gurss E, Hennes E. Near-infrared spectroscopy measurement of sacral tissue oxygen saturation in healthy volunteers immobilized on rigid spine boards. Prehosp Emerg Care. 2010;14:419-24

30. Theodore N, Hadley MN, Aarabi B, Dhall SS, Gelb DE, Hurlbert RJ, Rozzelle CJ, Ryken TC, Walters BC. Prehospital cervical spinal immobilization after trauma. Neurosurgery. 2013;72 Suppl 2:22-34

31. Deutsche Gesellschaft für Unfallchirurgie: S3 - Leitlinie Polytrauma/ Schwerverletzten-Behandlung 2011, AWMF-Register Nr. 012/019. (http:// www.awmf.org/leitlinien/detail////012-019.html).
32. White CC, Domeier RM, Millin MG. EMS spinal precautions and the use of the long backboard - resource document to the position statement of the National Association of EMS Physicians and the American College of Surgeons Committee on Trauma. Prehosp Emerg Care. 2014;18:306-14.

33. Walters BC, Hadley MN, Hurlbert RJ, Aarabi B, Dhall SS, Gelb DE, Harrigan MR, Rozelle CJ, Ryken TC, Theodore N. Guidelines for the management of acute cervical spine and spinal cord injuries: 2013 update. Neurosurgery. 2013:60 Suppl 1:82-91.

34. Deutsche Gesellschaft für Unfallchirurgie (DGU); Sektion Intensiv- \& Notfallmedizin SNA-AdUG: TraumaRegister DGU - Jahresbericht 2014. 2014. (http://www.dgu-online.de/qualitaet-sicherheit/schwerverletzte/ traumaregister-dgur.html).

35. Connor D, Greaves I, Porter K, Bloch M. Pre-hospital spinal immobilisation: an initial consensus statement. Emerg Med J. 2013:30:1067-9.

36. Haut ER, Kalish BT, Efron DT, Haider AH, Stevens KA, Kieninger AN Cornwell EE, 3rd, Chang DC. Spine immobilization in penetrating trauma: more harm than good? J Trauma. 2010;68:115-20. discussion 120-111.

37. Vaillancourt C, Stiell IG, Beaudoin T, Maloney J, Anton AR, Bradford P, Cain E, Travers A, Stempien M, Lees M, et al. The out-of-hospital validation of the Canadian C-Spine Rule by paramedics. Ann Emerg Med. 2009;54:663-671.e661.

38. Stiell IG, Wells GA, Vandemheen $\mathrm{KL}$, Clement CM, Lesiuk H, De Maio VJ, Laupacis A, Schull M, McKnight RD, Verbeek R, et al. The Canadian C-spine rule for radiography in alert and stable trauma patients. Jama. 2001;286:1841-8.

39. Hoffman JR, Mower WR, Wolfson AB, Todd KH, Zucker MI. Validity of a set of clinical criteria to rule out injury to the cervical spine in patients with blunt trauma. National Emergency X-Radiography Utilization Study Group. N Engl J Med. 2000;343:94-9.

40. Goldberg W, Mueller C, Panacek E, Tigges S, Hoffman JR, Mower WR. Distribution and patterns of blunt traumatic cervical spine injury. Ann Emerg Med. 2001;38:17-21.

41. Burton JH, Dunn MG, Harmon NR, Hermanson TA, Bradshaw JR. A statewide, prehospital emergency medical service selective patient spine immobilization protocol. J Trauma. 2006;61:161-7.

42. Meldon SW, Brant TA, Cydulka RK, Collins TE, Shade BR. Out-of-hospital cervical spine clearance: agreement between emergency medical technicians and emergency physicians. J Trauma. 1998:45:1058-61.

43. Barkana Y, Stein M, Scope A, Maor R, Abramovich Y, Friedman Z, Knoller N. Prehospital stabilization of the cervical spine for penetrating injuries of the neck - is it necessary? Injury. 2000;31:305-9.

44. Armstrong BP, Simpson HK, Crouch R, Deakin CD. Prehospital clearance of the cervical spine: does it need to be a pain in the neck? Emerg Med J. 2007:24:501-3.

45. Lin HL, Lee WC, Chen CW, Lin TY, Cheng YC, Yeh YS, Lin YK, Kuo LC. Neck collar used in treatment of victims of urban motorcycle accidents: over- or underprotection? Am J Emerg Med. 2011:29:1028-33.

46. Boissy P, Shrier I, Briere S, Mellete J, Fecteau L, Matheson GO, Garza D, Meeuwisse WH, Segal E, Boulay J, Steele RJ. Effectiveness of cervical spine stabilization techniques. Clin J Sport Med. 2011;21:80-8.

47. Connell RA, Graham CA, Munro PT. Is spinal immobilisation necessary for all patients sustaining isolated penetrating trauma? Injury. 2003;34:912-4.

48. Stuke LE, Pons PT, Guy JS, Chapleau WP, Butler FK, McSwain NE. Prehospital spine immobilization for penetrating trauma-review and recommendations from the Prehospital Trauma Life Support Executive Committee. J Trauma. 2011;71:763-9. discussion 769-770.

49. Perry SD, McLellan B, Mcllroy WE, Maki BE, Schwartz M, Fernie GR. The efficacy of head immobilization techniques during simulated vehicle motion. Spine (Phila Pa 1976). 1999;24:1839-44.

50. Hoffman JR, Wolfson AB, Todd K, Mower WR. Selective cervical spine radiography in blunt trauma: methodology of the National Emergency X-Radiography Utilization Study (NEXUS). Ann Emerg Med. 1998;32:461-9.

51. Vaillancourt C, Charette M, Kasaboski A, Maloney J, Wells GA, Stiell IG. Evaluation of the safety of $\mathrm{C}$-spine clearance by paramedics: design and methodology. BMC Emerg Med. 2011;11:1.

52. Vandemark RM. Radiology of the cervical spine in trauma patients: practice pitfalls and recommendations for improving efficiency and communication. AJR Am J Roentgenol. 1990:155:465-72.

53. Dunn TM, Dalton A, Dorfman T, Dunn WW. Are emergency medical technician-basics able to use a selective immobilization of the cervical spine protocol?: a preliminary report. Prehosp Emerg Care. 2004;8:207-11. 
54. Burton JH, Harmon NR, Dunn MG, Bradshaw JR. EMS provider findings and interventions with a statewide EMS spine-assessment protocol. Prehosp Emerg Care. 2005;9:303-9.

55. Domeier RM, Evans RW, Swor RA, Rivera-Rivera EJ, Frederiksen SM. Prehospital clinical findings associated with spinal injury. Prehosp Emerg Care. 1997;1:11-5.

56. Domeier RM, Frederiksen SM, Welch K. Prospective performance assessment of an out-of-hospital protocol for selective spine immobilization using clinical spine clearance criteria. Ann Emerg Med. 2005;46:123-31.

57. Domeier RM, Evans RW, Swor RA, Hancock JB, Fales W, Krohmer J, Frederiksen SM, Shork MA. The reliability of prehospital clinical evaluation for potential spinal injury is not affected by the mechanism of injury. Prehosp Emerg Care. 1999;3:332-7.

58. Hanson JA, Blackmore CC, Mann FA, Wilson AJ. Cervical spine injury: a clinical decision rule to identify high-risk patients for helical CT screening. AJR Am J Roentgenol. 2000;174:713-7.

59. Hasler RM, Exadaktylos AK, Bouamra O, Benneker LM, Clancy M, Sieber R, Zimmermann H, Lecky F. Epidemiology and predictors of spinal injury in adult major trauma patients: European cohort study. Eur Spine J. 2011;20:2174-80,

60. Bortsov AV, Platts-Mills TF, Peak DA, Jones JS, Swor RA, Domeier RM, Lee DC, Rathlev NK, Hendry PL, Fillingim RB, McLean SA. Pain distribution and predictors of widespread pain in the immediate aftermath of motor vehicle collision. Eur J Pain. 2013;17:1243-51.

61. Agrawal A. Cervical spine clearance: a review and understanding of the concepts. JNMA J Nepal Med Assoc. 2008:47:244-50

62. Muhr MD, Seabrook DL, Wittwer LK. Paramedic use of a spinal injury clearance algorithm reduces spinal immobilization in the out-of-hospital setting. Prehosp Emerg Care. 1999;3:1-6.

63. Myers LA, Russi CS, Hankins DG, Berns KS, Zietlow SP. Efficacy and compliance of a prehospital spinal immobilization guideline. Int J Emerg Med. 2009;2:13-7.

64. Anderson PA, Muchow RD, Munoz A, Tontz WL, Resnick DK. Clearance of the asymptomatic cervical spine: a meta-analysis. J Orthop Trauma. 2010;24:100-6.

\section{Submit your next manuscript to BioMed Central} and we will help you at every step:

- We accept pre-submission inquiries

- Our selector tool helps you to find the most relevant journal

- We provide round the clock customer support

- Convenient online submission

- Thorough peer review

- Inclusion in PubMed and all major indexing services

- Maximum visibility for your research

Submit your manuscript at www.biomedcentral.com/submit
Biomed Central 